Reception in the Town Gardens, Buxton.

The Mayor and Corporation of Buxton and the Buxton and High Peak Medical Society entertained members, ladies and guests of the Association in the Town Gardens to tea at 5.30 p.m. on July 28th. Subsequently members had an opportunity of visiting the Town Baths and Devonshire Hospital, where the modern installation for electro-therapeutic treatment was much admired.

\title{
Annual Dinner.
}

The Annual Dinner of the Association was held at 8 p.m. on Wednesday, July 28th, at the Palace Hotel, Buxton. The function was well attended, the usual " toasts" honoured and a happy evening spent. Ladies were included among the guests and it is hoped that their presence may be an annual event in future.

Owing to inclement weather the excursions arranged for the two following days had to be abandoned.

\section{IRISH DIVISION.}

The Sumarer Merting of the Irish Division was held on Thursday, June 24th, 1920, at Purdysburn Villa Colony, Belfast, by the kind invitation of Dr. Graham. Members present: Dr. Graham (in the Chair), Dr. Nolan, Dr. J. O'C. Donelan, Dr. Mills, Dr. Lawless, Dr. Patrick, Dr. Leeper (Hon. Secretary).

Letters of apology for unavoidable absence were received from Dr. Colles, K.C. Dr. Gavin, of Mullingar, Dr. Martin, of Letterkenny, Lt.-Col. W. R. Dawson and Dr. O'Doherty, Omagh.

The minutes of the previous meeting were read and signed.

A great deal of correspondence in connection with the General Nursing Council for Ireland was read, and it was proposed by Dr. Mills, seconded by Dr. Patrick and unanimously approved:

“That Dr. Nolan and Dr. J. O'C. Donelan be nominated by the Division as representatives of the Irish Division of the Medico-Psychological Association on the Sub-Committee of the General Nursing Council for Ireland.'

$A$ ballot for the election of an ordinary member was next proceeded with, Dr. Patrick and Dr. Mills being appointed scrutineers. The Chairman subsequently declared that Dr. J. P. Boland, Assistant Medical Officer of Ballinasloe Asylum, was elected a member of the Association.

The meeting next proceeded to consider important matters in connection with the Nurses' Registration Bill, and a letter was read from the Chief Secretary in reply to the communication addressed to him by direction of the Autumn Meeting of the Medico-Psychological Association. The following is the text of the letter:

\section{Chigf Secretary's Office,} Dublin Castle;

Fure 12 th, 1920.

Sir,-Referring to your letter of April 21 st last on the subject of the Constitution of the General Nursing Council for Ireland, I am directed by the Lord Justices to acquaint you, for the information of the Irish Division of the MedicoPsychological Association of Great Britain and Ireland, that the question of appointing a representative of the Asylum Medical Service or the mental nurses in Ireland will be considered in the event of a vacancy arising on the Nursing Council, or when the Council is being reappointed at the end of three years, if no vacancy occurs in the meantime.

I am to add that, as you are no doubt already aware, two representatives of the Irish Division of the Medico-Psychological Association have been invited to act on a special Sub-Committee of the General Nursing Council appointed to draft rules for the admission of mental nurses to the Register.

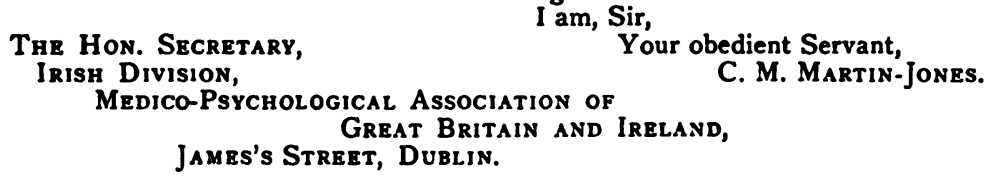


The Hon. Secretary was directed to write to the Chief Secretary acknowledging the receipt of his letter, and stating that the Irish Division was glad to hear that the first vacancy upon the Council was to be filled by a representative of the medical or nursing staffs of the asylums.

Questions in connection with the failure of the Government to give the asylum service any representation upon the General Public Health Council of Ireland were discussed.

Dr. Lawless sought the opinion of the members as regards the position of the staff in his asylum, the newly appointed Board having refused to pay the staff salaries owing to some temporary deadlock. Dr. Lawless received the advice of the members.

Subsequently the members visited the Villa Colony, the workshops and other features of interest in connection with the Institution.

Dr. Lawless having been called to the Chair, a cordial vote of thanks to Dr. Graham for his kindness and hospitality and for the very interesting day he had given to the members was proposed by Dr. Nolan, seconded by Dr. Donelan, and passed with acclamation.

The following letter has been circulated (vide Report of Quarterly Meeting, p. 66):

MEDICO-PSYCHOLOGICAL ASSOCIATION OF GREAT BRITAIN AND IRELAND.

\section{it, Chandos Street, Cavendish Souare, April 2nd, 1920.}

DeAr SiR

The Council of the Medico-Psychological Association of Great Britain and Ireland is most anxious that the scope and usefulness of the Association shall be extended, so that it keeps fully abreast of modern developments, and expresses the aims and aspirations of younger members. At the present time new clinics are springing up all over the country under the Ministry of Pensions, and it is believed that it will not be long before the Ministry of Health will provide early treatment for civilians suffering from mental and nervous disorders. This new departure was urged by the Medico-Psychological Association in 1914 and again in 1918, and we believe the Association can and should assist in carrying out this reform successfully.

The activities of the Association were necessarily curtailed by the war, but its members continued to render striking service to medicine during this time in divers fields of work, and now that a new era is at hand, the Council trusts that the Association may once again fulfil its proper function in promoting renewed interest in psychological medicine.

It is of the first importance that all the young men freshly returned from service under war conditions, especially those who have been engaged in research work or in the treatment of nervous and mental disorders, should become members of the Association, as it is to them we must look for inspiration and progress. Our membership should include all engaged in psychiatry, not merely those interested in the welfare of the insane, but all physicans devoting their energies to the study and treatment of nervous and mental disorders.

We believe the Association can render signal service to the community in facilitating the interchange of ideas, in stimulating research, and in publishing in its journal reports of success and of failure in treatment.

The object of the letter is to ask all our members to encourage anyone they know to be interested in psychiatry, whether engaged in hospitals, clinics, private institutions, or pension boards, to apply for membership. An appeal of this kind can, however, hardly be attended with success unless it is found to be worth while to join the Association.

The following facts may be mentioned :

(I) The Medico-Psychological Association has a membership extending throughout the whole of Great Britain and Ireland. 